\title{
Expanding boundaries of exploration
}

\author{
Mineral exploration is pushing new frontiers. Given a poor track record on land, mining practises should \\ be honed on home soil before venturing into the oceans.
}

Mining is a dirty business. Yet, the demand for metals is greater than ever - a theme discussed in this focus issue on economic geology (http://www.nature.com/ngeo/ focus/economic-geology/index.html). Close attention to an optimum use of resources with minimum waste and state-of-the art technology, as well as the recycling of used metal-rich devices and industrial large-scale infrastructure, can help meet this demand. But, to guarantee supply, the boundaries of exploration will have to be pushed. In the light of technological advances and growing opposition to large-scale mining projects in inhabited regions, deep-sea exploration and potentially even extra-terrestrial mining seem less utopic than just a decade or two ago.

September 2013 was a month of success for anti-mining protestors across the globe. At least partly in response to fierce local opposition, several large mining projects have been halted. For example, Anglo American has withdrawn from the Pebble mine project, which planned to exploit gold and copper reserves in Alaska's wilderness, and a bill to allow the company Gabriel Resources to mine gold and silver near the town of Roşia Montană, Romania, was initially rejected and remains under intense debate in the Romanian government. And rightly so, as assessments raised environmental concerns with each project. However, tight restrictions on projects in one location can lead to the expansion of mining processes elsewhere typically in less-developed countries, where health and safety standards are more lax and the livelihoods of locals depend on foreign investment. As with oil and gas exploration some time ago, potential sites for large-scale mining projects are now creeping towards the deep ocean.

The ocean's floors contain vast reserves of minerals, including manganese, iron, copper, nickel, gold and rare earth elements. The metals are stored in the sea floor, in nodules or around hydrothermal vents, some several thousand metres beneath the sea surface. Exploitation of these reserves is by no means a new idea, but it is only now becoming feasible, with higher metal prices and emerging technologies. Metal extraction from the deep sea floor, it seems, is right around the corner. For example, in 2011, the government of Papua New Guinea granted the company Nautilus Minerals Inc. the first lease to

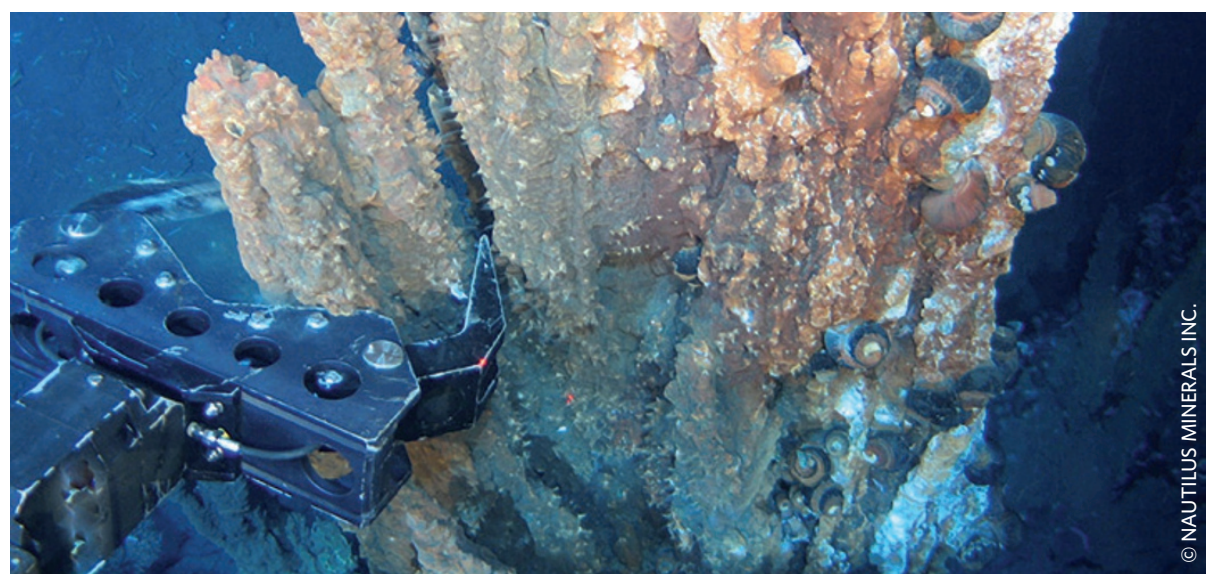

develop such a project in the Bismarck Sea. The company now aims to begin exploration and, if successful, hopes to expand into waters near Fiji, Tonga and New Zealand.

Such projects plan to dig up rocks from the sea floor and transport them to ships at the surface using hydraulic pumps ${ }^{1}$. But deepsea mining doesn't remove all environmental concerns from the inhabited land; once ground into slurry, the crushed mixture would be transported onshore for processing. Extracting the metals often requires large amounts of toxic chemicals, such as cyanide and mercury - a process with a poor track record on land. For example, in 2000, a cyanide spill from the Baia Mare gold mine in Romania contaminated the drinking water of 2.5 million people and was dubbed Europe's worst environmental disaster since Chernobyl. And small-scale, artisanal gold mining - a common and unregulated practice in cities such as La Rinconada, Peru - is now thought to be the leading source of mercury pollution globally ${ }^{2}$. As yet, it is unclear where the onshore processing of deep-sea minerals will take place, but it is likely that developing nations with lower safety restrictions will bear the brunt.

The deep oceans, and particularly the hydrothermal vents, are also home to a host of unique organisms, many of which we know little about ${ }^{3}$. Nautilus Minerals Inc. has worked with scientists to establish environmental guidelines ${ }^{4}$. The proposal is to set aside a conservation area that could be used to repopulate the mine site, if needed, once metal extraction is complete. However, whether that will be sufficient to protect diversity, and how large the far-field pollution would be, is still quite unclear.

The appetite for mining beyond the confines of the land does not end with the deep ocean: celestial bodies, too, have stirred commercial interest. For example, in 2012, the private company Planetary Resources based in Washington State, USA, announced plans to mine asteroids ${ }^{5}$. The company is only in the initial stages of development, but aims to build robotic spacecraft that can intercept, track and orbit asteroids, and transmit data on asteroid shape and composition back to Earth ${ }^{6}$. It is unclear how any minerals might be collected and returned to Earth, and these exploits currently seem to be economically unfeasible pipe dreams. But, at one time, exploration of the deep sea, too, seemed only science fiction.

The prospect of mining the ocean floors and bodies beyond Earth raises many ethical questions, not least those of ownership. And with no shortage of examples of mining gone horribly wrong, even on firm ground, it is hard to see how the infinitely higher risks of offshore and extra-terrestrial mining could possibly be controlled. As suggested in two Commentary pieces on pages 892 and 894 of this issue, we must explore all avenues including those closer to home. Only then should we venture into more difficult and unprotected terrains.

\footnotetext{
References

1. Schrope, M. Nature 495, 294 (2013).

2. Wade, L. Science 341, 1448-1449 (2013).

Witze, A. Nature Geosci. 5, 159 (2012).

4. Van Dover, C. L. Nature 470, 31-33 (2011).

5. Elvis, M. Nature 485, 549 (2012).

6. www.planetaryresources.com
} 